\title{
Interferons and IRF-1 Induce Expression of the Survival Motor Neuron (SMN) Genes
}

\author{
Sophie Baron-Delage, ${ }^{1}$ Annie Abadie, ${ }^{1}$ Andoni Echaniz-Laguna, ${ }^{2}$ \\ Judith Melki, ${ }^{2}$ and Laura Beretta ${ }^{1,3}$ \\ ${ }^{1}$ Institut National de la Santé et de la Recherche Médicale (INSERM), Curie \\ Institute, Paris, France \\ ${ }^{2}$ Laboratoire de Neurogénétique Moléculaire, INSERM E 9913, Genopole, \\ Evry, France. \\ ${ }^{3}$ Present address : Department of Microbiology and Immunology, University \\ of Michigan, Ann Arbor, Michigan, U.S.A
}

Accepted July 28, 2000.

\begin{abstract}
Background: Spinal muscular atrophy (SMA) is a common recessive disorder, characterized by degeneration of motor neurons of the spinal cord. Deletions, conversions, or mutations of the survival motor neuron gene (SMN) are responsible for SMA. A highly homologous centromeric copy of the SMN gene (SMNc) remains intact in SMA patients. However, there is an inverse correlation between the amount of the SMNc gene product and the clinical severity of the disease. An understanding of SMN and SMNC gene regulation is, therefore, an important step towards therapy for SMA.

Results: We identified a candidate InterferonStimulated Response Element (ISRE), overlapping with an Interferon Regulatory Factors binding motif (IRF-E) in the promoter region of SMN
\end{abstract}

and SMNc genes. Both ISRE and IRF-E motifs are involved in mediating transcriptional induction of interferon-stimulated gene expression. We, therefore, investigated whether SMN and SMNC genes were regulated by interferons (IFN). Here we show that both IFN- $\beta$ and IFN- $\gamma$ rapidly induced SMN and SMNC mRNA and protein expression in various cell lines. The transcription factor IRF-1 bound to the candidate ISRE/IRF-E sequence of SMN and SMNC genes in vitro and overexpression of IRF-1 induced expression of both genes in transfection assays. IRF-1 is, therefore, at least in part responsible for the induction of SMN and SMNc by IFNs. In primary culture of fibroblasts from SMA patients, IFN- $\beta$ and IFN- $\gamma$ induced SMNc gene expression and restored protein defect.

\section{Introduction}

The survival motor neuron gene, SMN, has been implicated as the disease-causing gene in spinal muscular atrophy (SMA) (1). SMN encodes a protein interacting with components of the spliceosomal complex, suggesting that SMN has a role in RNA processing $(2,3)$. The SMN

Address correspondence and reprint requests to: Dr. Laura Beretta, Department of Microbiology and Immunology, University of Michigan, Ann Arbor, MI 48109, U.S.A. Phone: 734-615-5964 ; Fax: 734-615-6150 ; E-mail: berettal@umich.edu gene is duplicated with an almost identical centromeric copy, SMNc. Loss of function of SMN in SMA patients can occur by deletions, gene conversion events, or point mutations; whereas, SMNc remains intact $(1,4-6)$. However, the relative amount of SMNC is markedly reduced in the most severe form, designated SMA type-I, compared with the mildest form of SMA, designated type-III. This suggests a direct correlation between the level of SMNc protein and the clinical severity of the disease $(7,8)$. The organization of the human SMN genes has been described (9) and the promoter region of both 
genes identified (10). We determined that the sequence (AAAGGAAAGGAAAT), located in the minimal promoter region of both SMN and SMNc genes, $65 \mathrm{nt}$ upstream of the transcription site, matches, although not perfectly, the consensus Interferon-Stimulated Response Element (ISRE) sequence (-GGAAAN(1-2)GAAACY) (11) and the consensus Interferon Regulatory Factors, IRF-1/IRF-2, binding sequence motif, termed IRF-E (-G(A)AAA $\left.{ }^{\mathrm{G}} / \mathrm{C}^{\mathrm{T}} / \mathrm{C}_{\mathrm{GAAA}}{ }^{\mathrm{G}} / \mathrm{C}^{\mathrm{T}} / \mathrm{C}^{-}\right)$ (12). ISRE and IRF-E elements are present in the 59flanking regions of many interferon (IFN)induced genes and regulate transcriptional induction of these genes after IFN treatment (13-15). We, therefore, investigated the effects of IFNs on SMN and SMNc gene expression.

\section{Materials and Methods}

\section{Cells, Reagents and Antibodies}

The human astrocytoma cell line Al72 (CRL1620) was obtained from the American Type Culture Collection (ATCC; Rockville, MD). The human oligodendroglioma HOG cell line (16) was a gift from Dr. F. Rieger (INSERM, France). The human primary fibroblasts from SMA patients were obtained from J.M. The cells were grown in Dulbecco's minimal essential media (DMEM; Life Technologies, Grand Island, NY) supplemented with $10 \%$ heatinactivated foetal bovine serum (Life Technologies, Grand Island, NY). Cells were subcultured the day preceeding IFN-treatments to initiate treatment of the cells in their exponential growth phase. Recombinant human interferons, rHuIFN- $\gamma$ and rHuIFN- $\beta$ were gifts from Roussel-Uclaf (Romainville, France) and AresSerono (Geneva, Switzerland), respectively.

Rabbit affinity-purified polyclonal antibodies against human IRF-1 and Signal transducers and activaters of transcription (Stat1) proteins were from Santa Cruz Biotechnology, Inc. (Tebu, France). To produce polyclonal antibodies against SMN, a synthetic peptide derived from the N-terminal end of SMN (residues 21-35) was used to immunize rabbits (Neosystem, Strasbourg, France). The best immune response was obtained with antiserum 739785 .

\section{Western Blots Analysis}

Cells were lysed by successive freeze-thaw cycles, in $20 \mathrm{mM}$ Tris- $\mathrm{HCl}$, pH 7.5 buffer, containing $5 \mathrm{mM}$ EDTA and $100 \mathrm{mM} \mathrm{KCl} .50$ or $100 \mu \mathrm{g}$ of protein were dissolved in sample buffer and the samples were loaded onto a sodium dodecyl sulfate (SDS) $10 \%$ polyacrylamide gel. Proteins were transferred onto a $0.22 \mu \mathrm{m}$ nitrocellulose membrane (Schleicher and Schuel, Dassel, Germany), which was incubated for $2 \mathrm{hr}$ with rabbit polyclonal antiserum against SMN (739785) at a dilution 1:2000, followed by horseradish peroxide (HRP)-labeled conjugate antibody at a dilution 1:2000. Immunodetection was realized by enhanced chemiluminescent protein (ECL) reagents and autoradiography (Amersham, Orsay, France). The blot was rehybridized with an antibody against actin to ensure that equal amount of proteins were present in each lane.

\section{RNA Extraction and Northern Blots Analysis}

Cells were scraped off directly into $4 \mathrm{M}$ guanidinium isothiocyanate [containing $25 \mathrm{mM}$ citratesodium, 0.1M 2-mercaptoethanol, Sarkosyl $0.5 \%$, (pH7.0)], and total RNA was isolated by centrifugation through a cushion of $5.7 \mathrm{M} \mathrm{CsCl}$ (17). $20 \mu \mathrm{g}$ of RNAs were loaded on a $1.2 \%$ agarose gel with $6 \%$ formaldehyde in $(\mathrm{N}$ morpholino) propanesulfonic acid. (MOPS) buffer, and then transferred onto a $0.45 \mu$ m nylon Hybond N1 membrane (Amersham). Northern blots were hybridized overnight at $428 \mathrm{C}$ using radiolabelled probe $\left(\begin{array}{lllll}2 & 3 & 10^{6} \mathrm{cpm} / \mathrm{ml}\end{array}\right)$. The cDNA probe for human SMN was a polymerase chain reaction (PCR) product of $864 \mathrm{bp}$. The cDNA probes were labelled using the Rediprime random primer labeling kit (Amersham), using $\left(\alpha{ }^{32} \mathrm{P}\right) \mathrm{dCTP}$. After hybridization, blots were washed to high stringency and analyzed with a PhosphorImager (Molecular Dynamics, Sunnyvale, CA). RNA was quantified and normalized by differential densitometric scanning of the SMN bands versus the 28SrRNA bands (18).

For determining the half-life of SMN mRNA, cells were incubated with $25 \mu \mathrm{g} / \mathrm{ml}$ of the RNA synthesis inhibitor 5,6-dichlorobenzimidazole riboside (DRB) (19) for different time periods of up to $15 \mathrm{hr}$ before lysis in guanidium isothiocyanate as described above.

\section{Reverse Transcription Polymerase Chain Reaction (RT-PCR)}

Single-stranded cDNA was synthesized from total RNA using Moloney's murine leukemia virus reverse transcriptase and random hexamers as primers. Preliminary experiments were performed to determine the conditions in 
which cDNAs were amplified in the linear region of the PCR reaction curve. The reaction mixture was composed of $10 \mu \mathrm{l}$ of cDNA template (diluted 1/50) obtained from $1 \mu \mathrm{g}$ of extracted RNA; 50 pmol for SMN/SMNc primers; 40 pmol for $\beta$-actin primers and 25 pmol for IRF-1 primers; $25 \mathrm{nmol}$ of each dNTP; $1.25 \mathrm{U}$ of Taq DNA polymerase; $10 \mu \mathrm{l}$ of 10x PCR buffer in a final volume of $100 \mu \mathrm{l}$. PCR amplification conditions were as follows: denaturation at 948C for $5 \mathrm{~min}$, amplification during 35 cycles composed of denaturation at $948 \mathrm{C}$ for $50 \mathrm{sec}$, annealing at $578 \mathrm{C}$ for $50 \mathrm{sec}$, and extension at $72 \mathrm{sC}$ for $20 \mathrm{sec}$, followed by a final extension at $728 \mathrm{C}$ for $10 \mathrm{~min}$. Two different pairs of SMN/SMNc primers were used. The primers 59CCTCCCATATGTCCAGATTCT-39 and 59-CCTTCCTTCTTTTTGATTTTGTtT-39 were designed in exon 6 and 7, respectively, to generate a 126-bp fragment. The lower case letter represents the base included for creating a unique Dra I restriction site, only present in the SMNc, but absent from the SMN CDNA PCR products (20). The primers 59 CCTCCCATATGTCCAGATTCT-39 and 59ACTGCCTCACCACCGTGCTGG-39were designed in exon 6 and 8 , respectively, to generate a 420 -bp and a 360 -bp fragment, depending on the alternative splicing of exon 7. The other nucleotide sequence of primers used were 59CAACttcATCCCGGGGCTCA-39 and 59-cctGaGGtAGCATgCGGTA-39for IRF-1 (21); 59ATCATGTTTGAGACCTTCAA-39 and 59TTGCGCTCAGGAGGAGCAAT-39 for $\beta$-actin cDNA sequences. Semiquantification of gene expression for SMN and SMNc was performed after coamplification and normalization with the $\beta$-actin internal control. The expression level for each transcript was evaluated after ethidium bromide staining by densitometric scanning using a video camera (Imager; Appligene, Illkirch, France) and analysis using Image 144611 MacIntosh software. Each PCR reaction was reproduced three times by sample.

\section{Electromobility Shift Assays}

All chemicals in this section are from Sigma St. Quentin, Fallavier, France. To prepare nuclear extracts, $20310^{6}$ cells were washed twice with ice-cold phosphate-buffered saline (PBS) and then resuspended in $200 \mu \mathrm{l}$ of buffer A [10 mM $\mathrm{N}$ - 2 - hydroxyethylpiperazine - N - 2 - ethanesulfonic acid (HEPES) pH 7.9, $60 \mathrm{mM} \mathrm{KCl}, 1 \mathrm{mM}$ EDTA, $10 \mathrm{mM}$ sodium orthovanadate, $0.5 \mathrm{mM}$ dithiothreitol and $0.1 \%$ Nonidet P-40] supple- mented with the following protease inhibitors: l $\mathrm{mM}$ phenylmethylsulfonyl fluoride and $5 \mu \mathrm{g} / \mathrm{ml}$ of leupeptin, aprotinin, pepstatin, antitrypsin and chymostatin. After swelling for 5 min on ice, nuclei were pelleted by centrifugation at $4000 \mathrm{rpm}$ for $5 \mathrm{~min}$, at $48 \mathrm{C}$. The nuclear pellet was then washed in the same buffer without Nonidet P-40 and resuspended in buffer B $(20 \mathrm{mM}$ Tris- $\mathrm{HCl}, \mathrm{pH} 8,1.5 \mathrm{mM}$ $\mathrm{MgCl}_{2}, 600 \mathrm{mM} \mathrm{KCL}, 0.2 \mathrm{mM}$ EDTA, $0.5 \mathrm{mM}$ dithiothreitol, $25 \%$ glycerol and the mixture of protease inhibitors described above). After two cycles of freezing/defrosting in nitrogen liquid, nuclear debris were centrifuged at $12000 \mathrm{x} g$ for $45 \mathrm{~min}$ at $48 \mathrm{C}$ and the supernatant was aliquoted and stored at $2808 \mathrm{C}$ until analysis by electromobility shift assays (EMSA). Protein was quantified using Bradford's assay.

For EMSA, proteins $(10 \mu \mathrm{g})$ were incubated with radiolabeled probe $(30000 \mathrm{cpm})$ in binding buffer $[(10 \mathrm{mM}$ Tris- $\mathrm{HCl}, \mathrm{pH}$ 7.4, $50 \mathrm{mM} \mathrm{NaCl}, 0.5 \mathrm{mM}$ dithiothreitol, 18\% glycerol, $0.2 \%$ Nonidet $\mathrm{P}-40$ and $2 \mu \mathrm{g}$ of poly $(\mathrm{dI}-\mathrm{dC})]$ in a total volume of $20 \mu \mathrm{l}$. After 30 min incubation on ice, the nucleoprotein complexes were loaded onto a 5\% nondenaturing acrylamide gel in TGE buffer (50 mM Tris- $\mathrm{HCl}, \mathrm{pH} 8.8,180 \mathrm{mM}$ glycline and $2.5 \mathrm{mM}$ EDTA) and migrated $3 \mathrm{hr}$ at $20 \mathrm{mAmp}$, in refrigerated conditions. The gel was dried and exposed overnight to a PhosphorImager screen (Molecular Dynamics, Sunnyvale, CA). For competition experiments, antisera were mixed directly with nuclear extracts and binding buffer 30 min at $48 \mathrm{C}$ before adding radiolabeled probe. Purified synthetic oligonucleotides were provided by Genset (Paris, France), and covered the SMN promoter fragment between 2224 and 2202 (59ctagaAAAGGAAAGGAAATATAACACAGt-39) (9). The lowercase letters represent the bases included for creating restriction sites. After annealing, the synthetic double-stranded oligonucleotides were end-labeled using the Klenow-DNA polymerase and $\left(\alpha-{ }^{32} \mathrm{P}\right) \mathrm{dCTP}$ (DuPont NEN) and were purified on Elutip ${ }^{\mathrm{TM}}$ columns (Schleicher \& Schuell).

\section{Transient Transfections}

$20310^{6}$ cells (logarithmic growth phase) were washed two times with serum-free DMEM and resuspended in $200 \mu \mathrm{l}$ of the same medium. Cells were then mixed gently with $16 \mu \mathrm{g}$ of the expression plasmid (pCMV)/IRF- 1 (a generous gift from Dr. J. Hiscott, Lady Davis Institute, 
Montreal, Canada) or of the vector alone pCMV together with $4 \mu \mathrm{g}$ of the pEGFP vector encoding the green fluorescence protein (Clontech, France) as a monitor for transfection efficiency. After $10 \mathrm{~min}$ on ice, cells were electroporated at $210 \mathrm{~V}, 960$ microfarads, using a Gene Pulser wired to an electroporation chamber (Bio-Rad, Ivry, France). Cells were then immediately diluted in $10 \mathrm{ml}$ of DMEM supplemented with $10 \%$ fetal bovine serum (FBS) and reseeded. 24 $\mathrm{hr}$ and $48 \mathrm{hr}$ after transfection, cells were harvested for preparing total cell extracts and total cellular RNA. Concurrently, cells were observed microscopically and transfection efficiency was evaluated.

For the analysis of the promoter of the SMN gene in response to IFNs and IRF-1, the plasmids containing the promoter of SMN or SMNc genes in front of the chloramphenicol transferase (CAT) reporter gene, 121PBL and 54PBL, respectively (10), were transfected alone or with the pCMV/IRF-1 plasmid, in Al72 cells as previously described. $24 \mathrm{hr}$ after transfection, cells were treated when indicated with IFN- $\beta$ or IFN- $\gamma$, and $48 \mathrm{hr}$ after transfection, CAT activity was measured.

\section{Results}

\section{IFNs Induce SMN Gene Expression}

We developed a rabbit polyclonal antibody to SMN (739785), raised against peptide sequence (amino acids 21-35) in the N-terminal domain of SMN. Figure IA shows a Western blot of HeLa cells demonstrating that the antibody detects a $38 \mathrm{kD}$ protein. Human Al72 astrocytoma cells were treated with IFN- $\beta$ or IFN- $\gamma$ for $16 \mathrm{hr}$ and SMN protein level was analyzed by Western blots. The relative intensity of the SMN protein band was increased 3 -fold in both IFN- $\beta$ - or IFN- $\gamma$-treated cells, relative to control, as determined by densitometric analysis (Fig. 1B, left panel). This induction was not limited to A172 cells treated with IFN- $\beta$ and IFN- $\gamma$, since similar results were obtained with human oligodendroglioma HOG cells (Fig. 1B, right panel), fibroblasts (see Fig. 7C), lymphoblastoid, and myeloid cells (data not shown). Induction of SMN protein by IFN- $\beta$ was apparent after $16 \mathrm{hr}$ and was maximal after $24 \mathrm{hr}$; whereas, induction of SMN by IFN- $\gamma$ was detected as early as $8 \mathrm{hr}$ after treatment and peaked after $16 \mathrm{hr}$ (Fig. 1C). Therefore, SMN protein expression was induced by both type I and type II IFNs (respectively, IFN- $\beta$ and IFN- $\gamma$ ) to the same extent. However, the response to IFN- $\gamma$ was more rapid than the response to IFN- $\beta$, and transient.

Northern blots analysis of SMN mRNA in A172 cells also showed an up-regulation of SMN mRNA after IFN- $\beta$ or IFN- $\gamma$ treatment, with a maximum induction of 4 -fold (Fig. 1D). As observed at the protein level, IFN- $\gamma$ induction of SMN mRNA was more rapid than IFN$\beta$ induction. Maximal induction of SMN mRNA occured between 8 and $16 \mathrm{hr}$ following IFN- $\beta$ treatment; whereas, after treatment with IFN- $\gamma$, the induction of SMN mRNA was transient and already maximal at $4 \mathrm{hr}$. Hence, there was a strong correlation between the induction of SMN mRNA and SMN protein levels.

\section{IFNs Induce SMN and SMNc Gene Expression to the Same Extent}

Immunoblotting and Northern blots analyses of SMN did not allow a distinction between products of the SMN gene and of its homologue SMNc. To compare the induction of the two genes by IFNs, RT-PCR coamplification of transcripts from both genes was undertaken, creating a unique Dra I site that only was present in the SMNc but absent from the SMN CDNA PCR products. Induction of SMN/SMNC expression was readily detected in IFN- $\beta$ - and in IFN- $\gamma$-treated cells (Fig. 2, upper panel). A faster response was observed with IFN- $\gamma$, compared with IFN- $\beta$ treatment, in agreement with the results of Northern blots analysis. Enzymatic digestion allowed separation of SMN and SMNC cDNA PCR products. We first observed that expression of the SMN gene in control A172 cells markedly was stronger than that of SMNc. Treatment with IFN- $\beta$ or IFN- $\gamma$ resulted in an induction of 4-fold of both SMN and SMNc genes, with comparable kinetics (Fig. 2, lower panel). Therefore, IFN- $\beta$ and IFN- $\gamma$ induced SMN and SMNc gene expression to the same extent.

\section{Stability of SMN and SMNc mRNAs}

Next we determined the contribution of SMN and SMNc mRNAs stability to the quantitative differences in the levels of RNA products of the two genes, and to their response to IFNs. Al72 cells were treated with IFN- $\beta$ or IFN- $\gamma$ for $8 \mathrm{hr}$. Control and treated cells were incubated with 


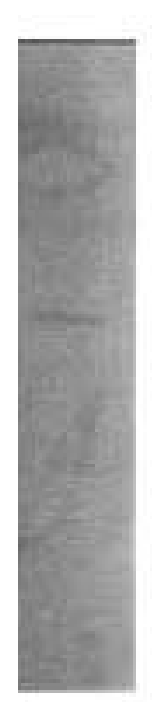

a

A)

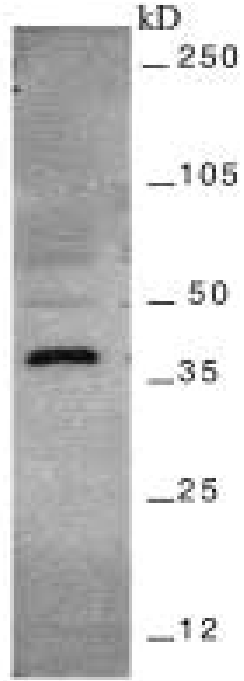

b

B)

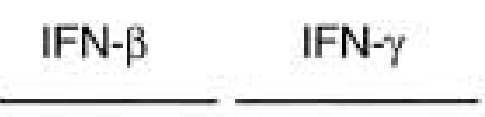

C 8 h $16 \mathrm{~h} 24 \mathrm{~h} 8 \mathrm{~h} 16 \mathrm{~h} 24 \mathrm{~h}$

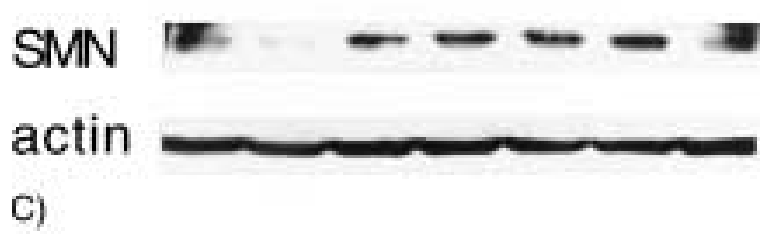

Fig. 1. Induction of survival motor neuron gene (SMN) expression in interferon (IFN)treated cells. (A) HeLa cell proteins $(50 \mu \mathrm{g})$ were solubilized and run on a $12 \%$ polyacrylamide gel and blotted. The Western blot was cut into two strips and each strip was probed with (a) the preimmune serum or (b) the immune serum (739785) at a dilution 1:2000. (B) $24 \mathrm{hr}$ after subculture, exponentially growing A172 and HOG cells were treated with or control without $1000 \mathrm{U} / \mathrm{ml}$ of IFN- $\beta$ or 1000 $\mathrm{U} / \mathrm{ml}$ of IFN- $\gamma$. After $16 \mathrm{hr}$ of culture, cells were lysed and total protein extracts $(50 \mu \mathrm{g})$ were analyzed by Western blots analysis, using the polyclonal antibody against SMN (739785) (1:2000) followed by horseradish (HRP)-labeled conjugate antibody at a dilution 1:2000. Immunodetection was realized by enhanced chemiluminescent protein (ECL) reagents

$25 \mu \mathrm{g} / \mathrm{ml}$ of DRB, a potent inhibitor of RNA synthesis. In the time course experiment, RTPCR analysis showed a progressive decline in the level of SMN/SMNc transcripts following treatment with DRB (Fig. 3A). Following digestion of the RT-PCR products with Dra I and separation of SMN and SMNc transcripts, we

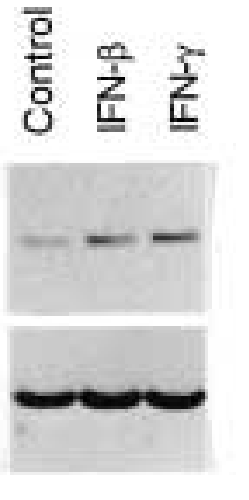

A172

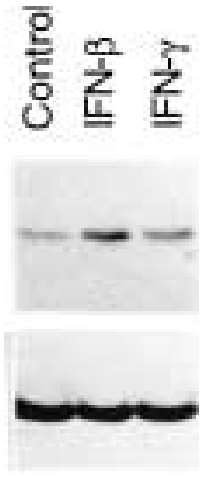

HOG

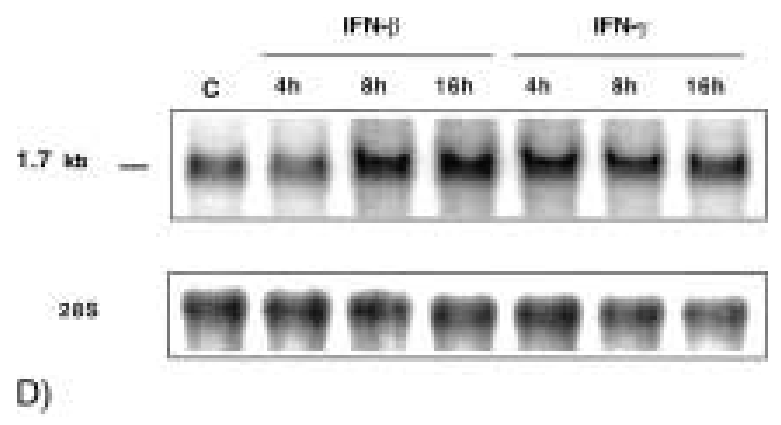

and autoradiography. The blot was rehybridized with a monoclonal anti-actin antibody to ensure that equal amount of proteins were present in each lane. (C) Total cell extracts from untreated (C) or treated Al72 cells for 8,16 and $24 \mathrm{hr}$ with IFN- $\beta$ (1000 $\mathrm{U} / \mathrm{ml})$ or IFN- $\gamma(1000 \mathrm{U} / \mathrm{ml})$ were analyzed by Western blots analysis, using anti-SMN and antiactin antibodies as described in (B). (D) A172 cells were cultured for the indicated time periods or control with medium alone (C) in the presence of IFN- $\beta$ $(1000 \mathrm{U} / \mathrm{ml})$ or IFN- $\gamma(1000 \mathrm{U} / \mathrm{ml})$. Total cellular RNA (20 pg/lane) was subjected to agarose gel electrophoresis, transferred to nylon membrane, and hybridized with a $\left({ }^{32} \mathrm{P}\right)$-labeled human SMN cDNA probe. Filters were subsequently hybridized to a $28 \mathrm{~S}$ rRNA oligonucleotide probe as a control of RNA loading.

determined that the difference in expression levels of SMN and SMNC mRNAs in control A172 cells was not due to different stabilities, as both mRNAs had an estimated half-life of 8 hr. Furthermore, IFN- $\beta$ and IFN- $\gamma$ did not modulate significantly either SMN, nor SMNc mRNA stability, as the decline in both mRNA 


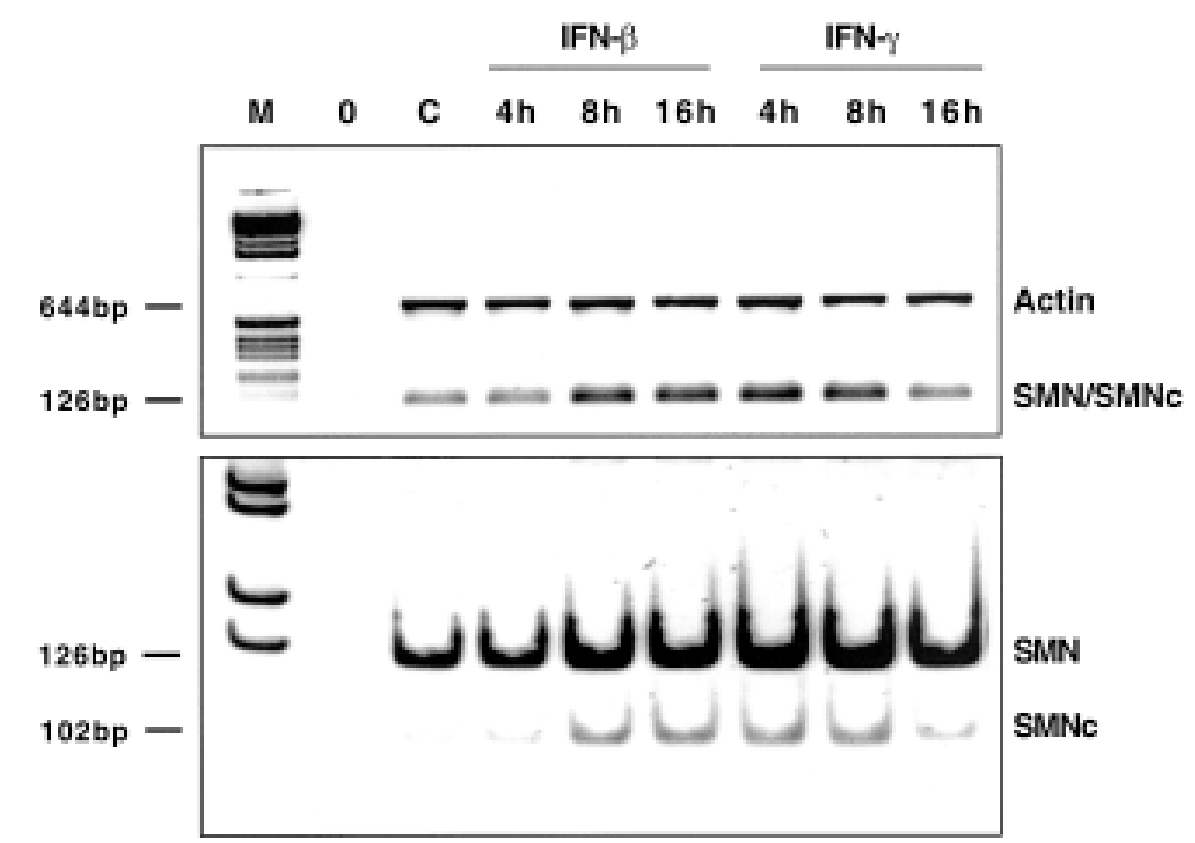

Fig. 2. Induction of SMN and SMNc mRNAs in interferon (IFN)-treated A172 cells. Total RNA $(1.5 \mu \mathrm{g})$ from Al72 cells treated for the indicated time periods with medium alone $(\mathrm{C})$ or in the presence of IFN- $\beta(1000 \mathrm{U} / \mathrm{ml})$ or IFN- $\gamma(1000$ $\mathrm{U} / \mathrm{ml}$ ) was reverse transcribed and polymerase chain reaction (PCR) coamplification was performed for SMN/SMNc and actin genes as described in "Materials and Methods." The prod-

levels followed similar kinetics in IFN-treated cells, compared with control cells (Fig. 3B).

IRF-1 Participates in IFN-induced SMN and SMNc Expression

To characterize the molecular basis of IFNinduction of SMN and SMNc genes, nuclear protein extracts prepared from untreated cells and from cells stimulated for 2 hr with IFN- $\beta$ or IFN- $\gamma$ were utilized for electromobility shift assays with radiolabeled, double-stranded, synthetic oligonucleotides encompassing the putative ISRE/IRF-E motif found in the promoter region of both SMN and SMNc genes. The formation of three major protein-DNA complexes was observed after treatment with IFN- $\beta$ (complexes $\mathrm{C} 1, \mathrm{C} 2$, and $\mathrm{C} 3$ ) or IFN- $\gamma$ (complexes $\mathrm{C} 4, \mathrm{C} 5$, and $\mathrm{C} 6$ ) and the pattern of protein-DNA complexes was similar after either treatments (Fig. 4A). ISRE is an element known to bind Interferon-stimulated Factor 3 (ISGF3), a heterotrimeric transcription factor consisting of Stat1, Stat2, and p48 (ISGF3 $\gamma$ ) (22). IRF-E is the consensus binding site for the IRF-1 transcription factor (23). Antibodies ucts were analyzed on a $2 \%$ agarose gel, visualized by ethidium bromide staining (upper panel), or previously subjected to digestion with Dra I and analyzed by $7 \%$ polyacrylamide gel electrophoresis (lower panel). The size of the PCR product for SMN, SMNc, and actin are, respectively, $126 \mathrm{bp}$, $102 \mathrm{bp}$, and $165 \mathrm{bp}$. Lane (0) represents the negative control, which was the product of PCR where RNA was omitted.

against IRF-1 and Stat l were, therefore, used to probe the protein-DNA complexes for the presence of corresponding proteins. Addition of antisera against the IRF-1 protein impaired or strongly reduced the formation of two proteinDNA complexes induced by both IFN- $\beta$ and IFN- $\gamma$. C2, C3 and C5, C6, respectively; (Fig. 4A; compare lanes 2 and 3, and lanes 6 and 7). Addition of antisera against the Stat 1 subunit impaired the formation of the upper protein-DNA complex $\mathrm{Cl}$, induced by IFN- $\beta$, but did not modify the upper IFN- $\gamma$-induced protein-DNA complex $\mathrm{C} 4$. These results suggested that IRFl was part of the major complexes induced by both IFN- $\beta$ and IFN- $\gamma$. Stat 1 was part of a complex induced only by IFN- $\beta$; whereas, another complex induced by IFN- $\gamma$ implicated a factor different from IRF-1 and Statl that remains unidentified.

IRF-1 expression following IFNs treatment in A172 cells was investigated by RT-PCR amplification of IRF-1 transcript (Fig. 4B). Expression of IRF-1 was induced by both IFN- $\beta$ and IFN- $\gamma$, with a stronger effect observed following IFN- $\gamma$ treatment. The induction of IRF- 1 was maximal as early as $4 \mathrm{hr}$ after IFN- $\gamma$ 


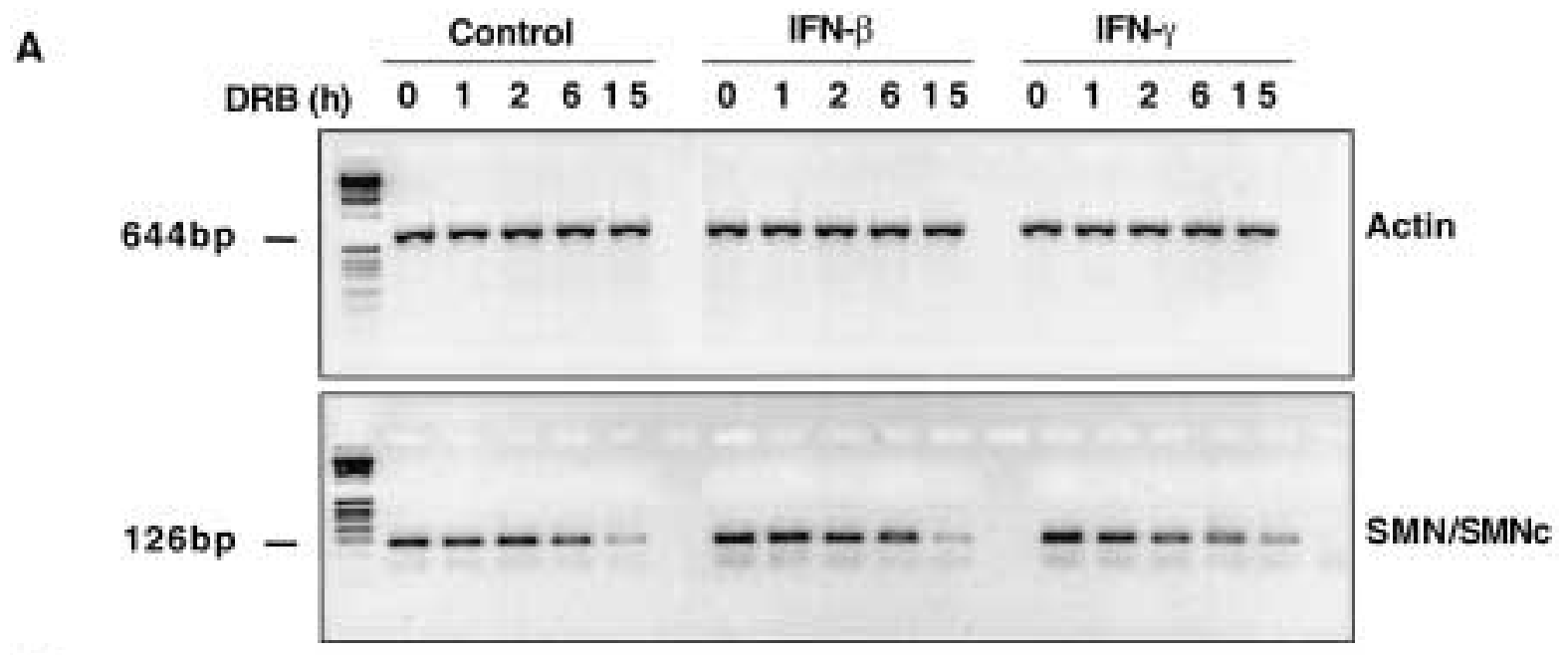

B

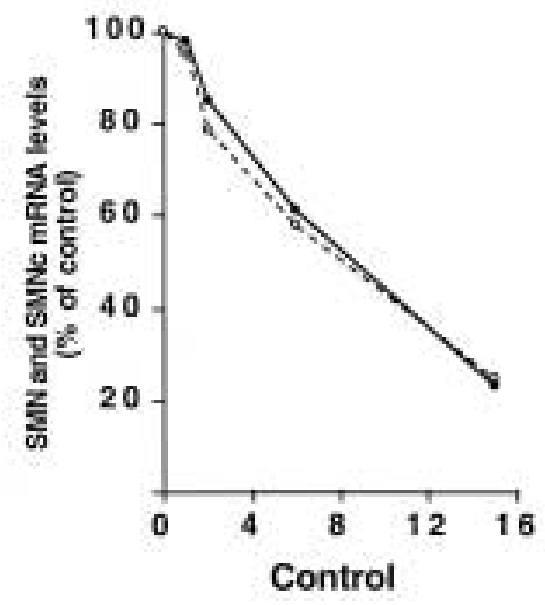

Fig. 3. Stability of SMN and SMNC mRNAs in control and interferon (IFN)-treated A172 cells. A172 cells pretreated with medium alone (Control), IFN- $\beta(1000 \mathrm{U} / \mathrm{ml})$, or IFN- $\gamma(1000 \mathrm{U} / \mathrm{ml})$ for $8 \mathrm{hr}$ were subsequently treated with $25 \mu \mathrm{g} / \mathrm{ml} \mathrm{5,6-}$ dichlorobenzimidazole riboside (DRB) for the indicated time periods, followed by RNA extraction. (A) reverse transcription-polymerase chain reaction

treatment; whereas, induction of IRF-1 was maximal after $8 \mathrm{hr}$ of IFN- $\beta$ induction. Therefore, in IFN-treated A172 cells, there was a strong correlation among expression of IRF-1, SMN, and SMNc genes.

\section{Overexpression of IRF-1 Trans-activates SMN and} SMNc Gene Expression

An IRF-1 expression plasmid was transfected into A172 cells as a direct approach to determine the effect of IRF-1 on the expression of SMN and SMNc in intact cells. The expression plasmid pCMV/IRF-1 or the vector alone were transfected together with a construct encoding

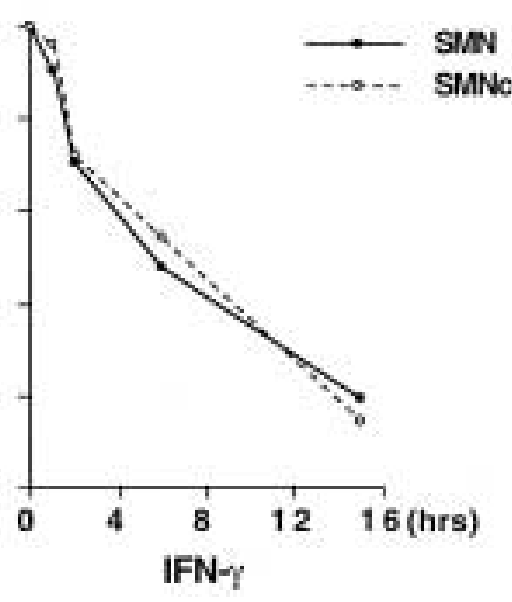

(RT-PCR) was performed for SMN, SMNc, and actin genes as described in "Materials and Methods" and the products were analyzed on a $2 \%$ agarose gel, or (B) previously digested with Dra I, analyzed on a $7 \%$ polyacrylamide gel, and the amounts of SMN and SMNC were quantified and expressed as percentages of initial values measured in the appropriate controls.

the green fluorescence protein (GFP) as a monitor for transfection efficiency. The transfection efficiency was similar $(18 \%)$ in the control pCMV- and pCMV/IRF-1 transfected cells. IRF-1, SMN, and SMNc gene expression was analyzed $24 \mathrm{hr}$ and $48 \mathrm{hr}$ post-transfection, by RT-PCR amplification (Fig. 5A). As expected, IRF-1 expression was not detected in cells transfected with the vector alone; whereas, IRF-1 mRNA was detected as early as $24 \mathrm{hr}$ after transfection and was maximal $48 \mathrm{hr}$ after transfection with the pCMV/IRF-1 plasmid. Both SMN and SMNc gene expression were induced in cells transfected with the IRF-1 plasmid, compared with cells transfected with the 


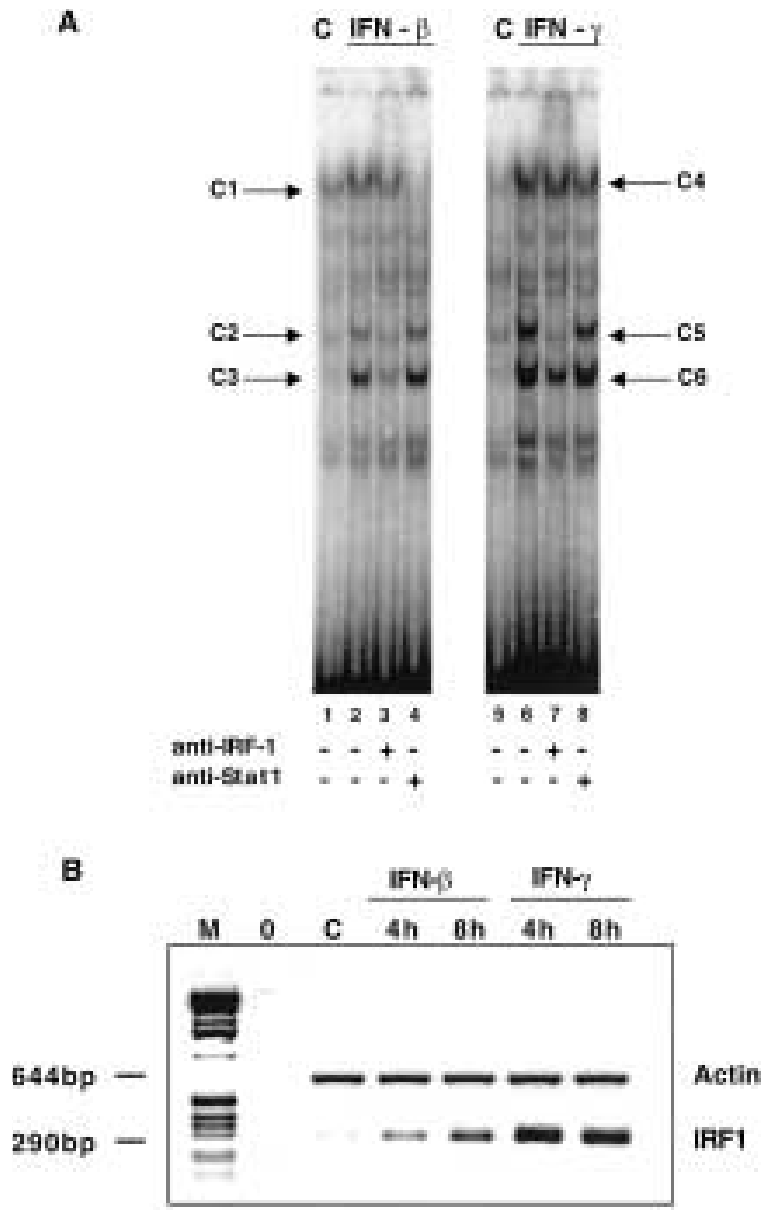

Fig. 4. Interferon regulatory factor (IRF)-1 participates in interferon (IFN)-induced expression of SMN and SMNc genes. (A) Nuclear extracts prepared as described in "Materials and Methods" from untreated (lanes 1, 5), IFN- $\beta$-treated (lanes $2-4$ ), or IFN- $\gamma$-treated (lanes 6-8) were assayed for specific binding activity to an oligonucleotide probe corresponding to SMN fragment 2224 to 2202 (9), after a 30 min preincubation without (lanes 1, 2, 5, 6) or with rabbit affinity-purified polyclonal antibodies against human IRF-1 (lanes 3, 7) or signal transducers and activators of transcription (Statl; lanes 4, 8). Arrows indicate $\mathrm{C} 1-, \mathrm{C} 2-$, and $\mathrm{C} 3$-specific proteinDNA complexes in IFN- $\beta$-treated cells and C4-, C5-, and C6-specific protein-DNA complexes in IFN$\gamma$-treated cells. (B) Total RNA from Al72 cells treated for $4 \mathrm{hr}$ and $8 \mathrm{hr}$, with medium alone (control; C) or in the presence of IFN- $\beta(1000 \mathrm{U} / \mathrm{ml})$ or IFN- $\gamma$ $(1000 \mathrm{U} / \mathrm{ml})$ was reverse-transcribed and polymerase chain reaction (PCR) coamplification was performed for IRF- 1 and $\beta$-actin genes, as described in "Materials and Methods." The products were analyzed on a $\mathbf{2} \%$ agarose gel and visualized by ethidium bromide staining.

vector alone. The effect also was stronger $48 \mathrm{hr}$ after transfection, compared with $24 \mathrm{hr}$. Western blots analysis showed an increase in SMN protein level in IRF-1-transfected cells after $48 \mathrm{hr}$, compared with control cells (Fig. 5B). Overexpression of IRF-1 was, thus, sufficient to transactivate SMN and SMNC gene expression in A172 cells.

This effect was direct, as shown by transfection assays using reporter plasmids containing the promoter of SMN or SMNC genes in front of the CAT gene, designated SMN-CAT and SMNC-CAT, respectively. Treatment of the transfected cells with IFN- $\beta$ or IFN- $\gamma$, or cotransfection with the IRF-1 plasmid, resulted in a significant increase in CAT activity (Fig. 5C). Similar results were obtained with both reporter plasmids, SMN-CAT and SMNC-CAT, as expected. These results demonstrated an interferon response, as well as an IRF-1 response, in the promoter activity of both SMN genes.

\section{IFNs Induce SMNc Gene Expression in Fibroblasts from SMA Patients}

The effect of treatment with IFNs on SMNc expression was examined using primary cultures of fibroblasts from skin biopsies of type-I (the most severe form) and type-II (the intermediate form) patients. Immunoblotting demonstrated that the amount of the SMNc protein was reduced in the two SMA type-I (SMAl and SMA2) and the one SMA type-II (SMA3) fibroblasts analyzed, relative to controls (C1 and C2) (Fig. 6A). Induction of SMN and SMNc gene expression was detected by RTPCR analysis for both IFN- $\beta$ - and IFN- $\gamma$-treated control fibroblasts, with a faster response to IFN- $\gamma$ (Fig. 6B). We evaluated SMN/SMNC mRNA expression by RT-PCR amplification, in control and SMA fibroblasts, following IFN- $\beta$ and IFN- $\gamma$ treatment (Fig. 7A; upper panel). Following digestion of the PCR products with Dra I and separation of SMN and SMNC CDNA PCR products, we detected expression of both SMN and SMNC genes in control cells, and of only the SMNC gene in SMA fibroblasts (Fig. 7A; lower panel). SMNc mRNA expression was induced following treatment with IFN- $\beta$ or IFN- $\gamma$, in SMA type-I and type-II patients. Previous reports show that SMNc gene produces an alternatively spliced isoform lacking exon 7, in addition to the full-length transcript; whereas, SMN gene generates primarily full-length mRNA $(1,24)$. The truncated protein corresponding to transcripts lacking exon 7 shows reduced self-association, a potential biochemical defect in SMA (25). Since the RTPCR assay system we used only detected the 
A
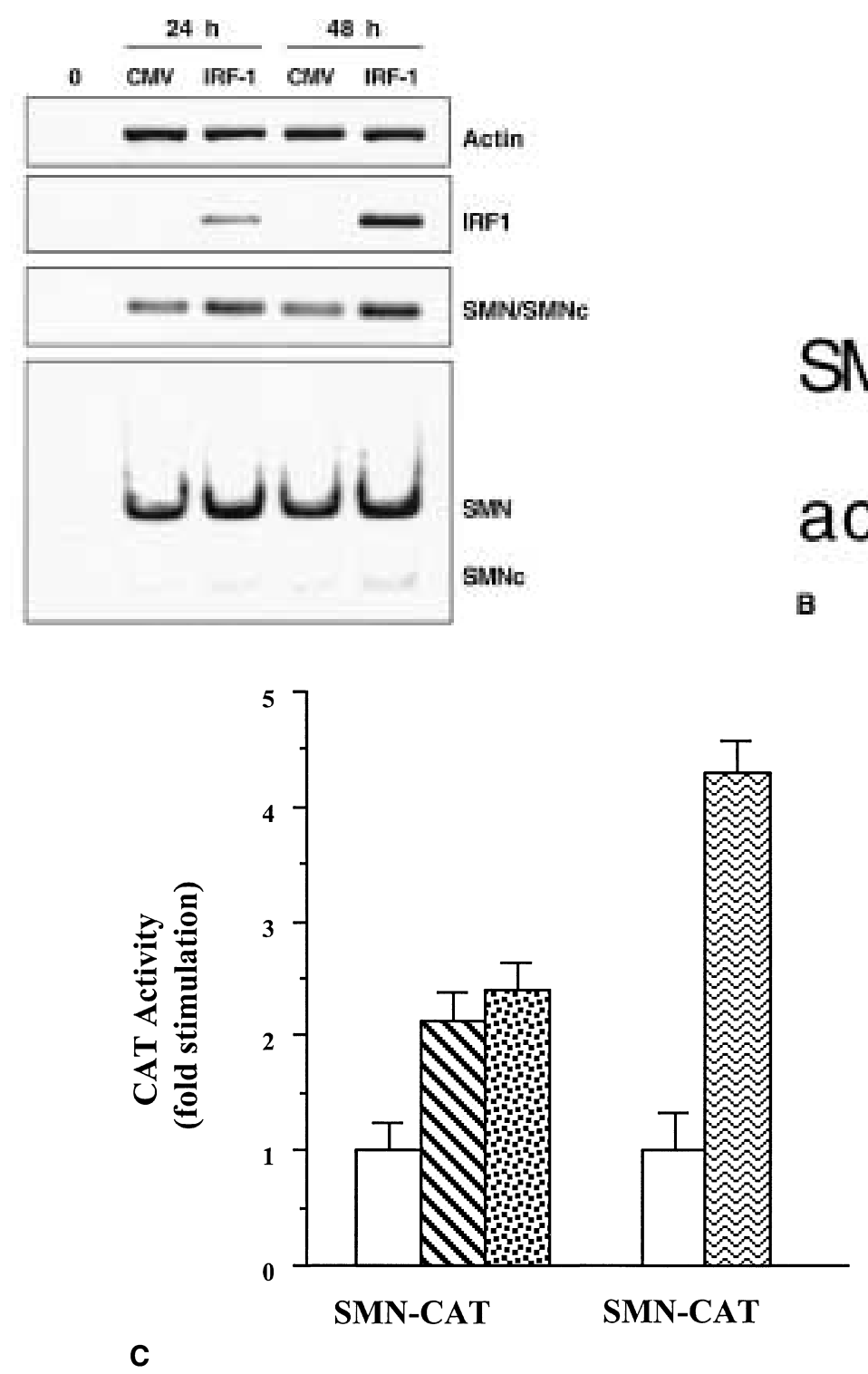

B

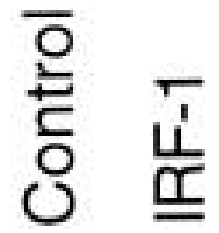

SMN

\section{actin}
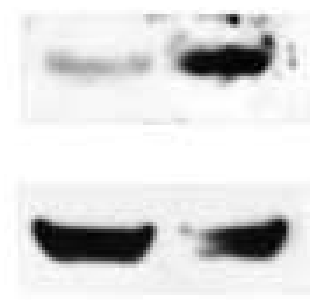

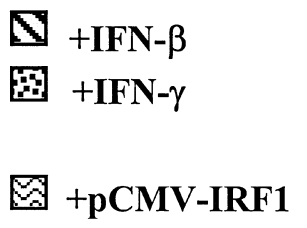

the SMN-chloramphenicol transferase (CAT) plasmid, alone or with pCMV/IRF-1 as described in "Materials and Methods." When indicated, cells were treated $24 \mathrm{hr}$ after transfection with interferon (IFN)- $\beta(1000 \mathrm{U} / \mathrm{ml})$ or IFN- $\gamma(1000 \mathrm{U} / \mathrm{ml})$. CAT activity was determined after $48 \mathrm{hr}$. The SMN promoter response (fold induction) is the ratio of CAT activity in stimulated or co-transfected cells to that in unstimulated cells, which is defined as 1.0. Values are means of four independent experiments. Identical results were obtained with the SMNc-CAT plasmid.

full-length transcripts, we wished to investigate whether IFN treatment also resulted in increased levels of the alternatively spliced SMNC transcript in SMA patients. RT-PCR amplification, using a pair of SMN/SMNc primers located in exons 6 and 8, was performed with RNA obtained from control and SMA fibro-

blasts. Expression of full-length and alternatively spliced transcripts differed between controls and SMA patients (Fig. 7B) in agreement with other studies previously reported (1). Expression of both transcripts retaining or lacking exon 7 was induced following treatment with IFN- $\beta$ and IFN- $\gamma$ in controls, as well 


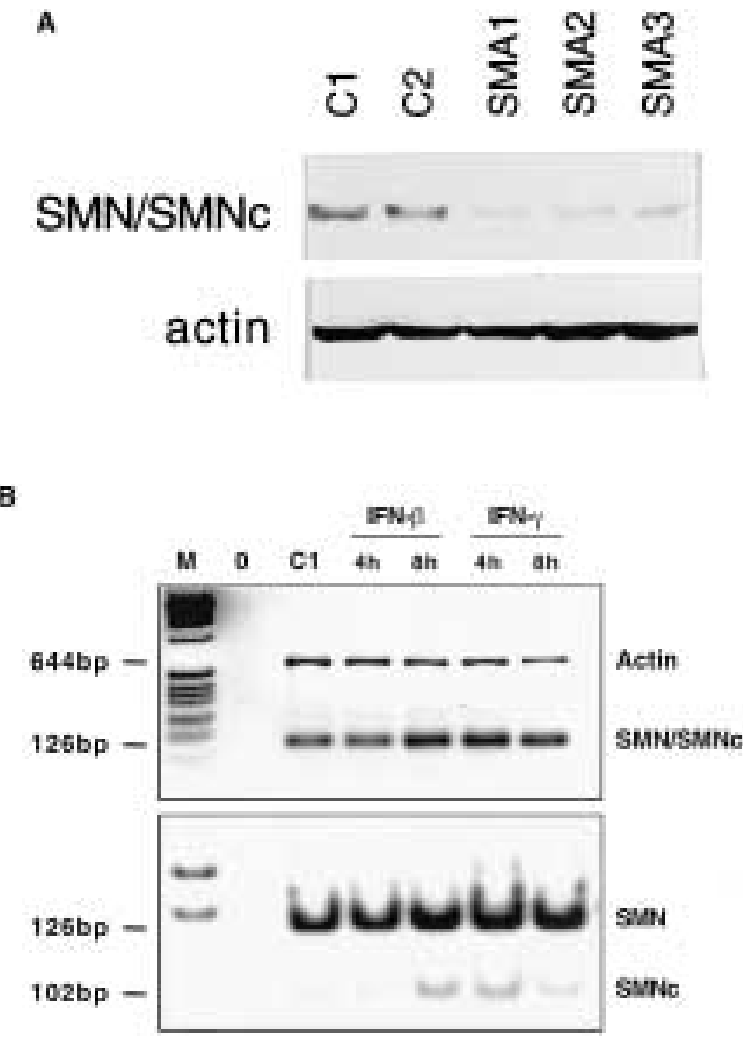

Fig. 6. Induction of SMN and SMNc gene expression in interferon (IFN)-treated fibroblasts. (A) Total protein extracts (100 $\mu \mathrm{g} / \mathrm{lane})$ from fibroblasts of control (C1, C2) and of type-I (SMA1, SMA2) or type-II (SMA3) Spinal muscular atrophy (SMA) patients were analyzed by Western blots analysis, as previously described in Fig. 1 using the anti-SMN antiserum (1:1000). (B) Total RNA from control fibroblasts (C1) untreated or treated for $4 \mathrm{hr}$ and $8 \mathrm{hr}$ with IFN- $\beta(1000 \mathrm{U} / \mathrm{ml})$ or IFN- $\gamma(1000 \mathrm{U} / \mathrm{ml})$ was reversed-transcribed and polymerase chain reaction (PCR) coamplification was performed for SMN/SMNc and actin genes, as described previously. The products were analyzed on a $2 \%$ agarose gel (upper panel) or previously digested with Dra I and analyzed by $7 \%$ polyacrylamide gel electrophoresis (lower panel). Lane (0) represents the negative control, which was the product of PCR where RNA was omitted.

as in SMA patients. In SMA3 fibroblasts, the interferons induced preferentially the transcript lacking exon 7 . Western blots analysis showed an increase in SMNc protein level in SMA fibroblasts following treatment with IFN- $\beta$ or IFN- $\gamma$ (Fig. 7C, and data not shown). In most cases analyzed, including SMA2 and SMA3, IFN- $\beta$ and IFN- $\gamma$ induced SMNc protein expression to comparable levels as seen in control fibroblasts. However, in SMAl fibroblasts, in which the level of SMNc was the low- est, IFN-treatment restored only partially SMNC protein level (Fig. 7C). IFN- $\beta$ and IFN- $\gamma$ treatment was, thus, sufficient to induce SMNc protein expression in fibroblasts from SMA, to levels close to those observed in control fibroblasts.

\section{Discussion}

In the present study, we provide the first evidence for an induction of SMN and SMNC genes expression. Expression of SMN and SMNc genes are induced by IFN- $\beta$ and IFN- $\gamma$ and both genes respond to IFNs to the same extent. Of particular relevance is that IFN- $\beta$ and IFN- $\gamma$ induce SMNc expression in fibroblasts from SMA patients. The induction of SMN and SMNc gene expression by IFNs is moderate. However, a 3-fold induction is sufficient to compensate for the SMNc protein defect in SMA (8). Characterization of the candidate ISRE/IRF-E element present in the promoter of both SMN and SMNc genes, by deletion and point mutations, is currently under investigation.

SMN protein has been shown to bind directly to a number of proteins that participate in early spliceosome assembly, suggesting it plays a role in RNA processing $(2,3,26)$. SMN is present in several intranuclear structures termed "gems", closely associated with coiled bodies and nucleoli $(27,28)$. The finding that SMN and SMNC are IFN-inducible genes suggests that they may participate in function of interferons (29-32). Our results demonstrate also that the transcription factor IRF-1 participates in the induction of SMN and SMNC gene expression by IFNs. IRF- 1 is a member of a growing family of IRFs (15). IRF- 1 is expressed at low levels or is undetectable in a variety of cell types. However, its expression is inducible by viral infection, by double-stranded RNA, by treatment with both type-I and type-II IFNs, as well as by other cytokines. IRF-1 has been shown to modulate not only the cellular response to IFNs and viral infection, but also to be involved in cell growth, susceptibility to transformation by oncogenes, and induction of apoptosis. It is possible that SMN and SMNC may participate in the induction of these IFN- and IRF-1 mediated cellular responses. Determination of a role of SMN genes in the IFN-mediated antiviral response of cells may be of considerable relevance to the SMA disease process. Given that SMNc expression level is directly correlated to the clinical severity of 
A

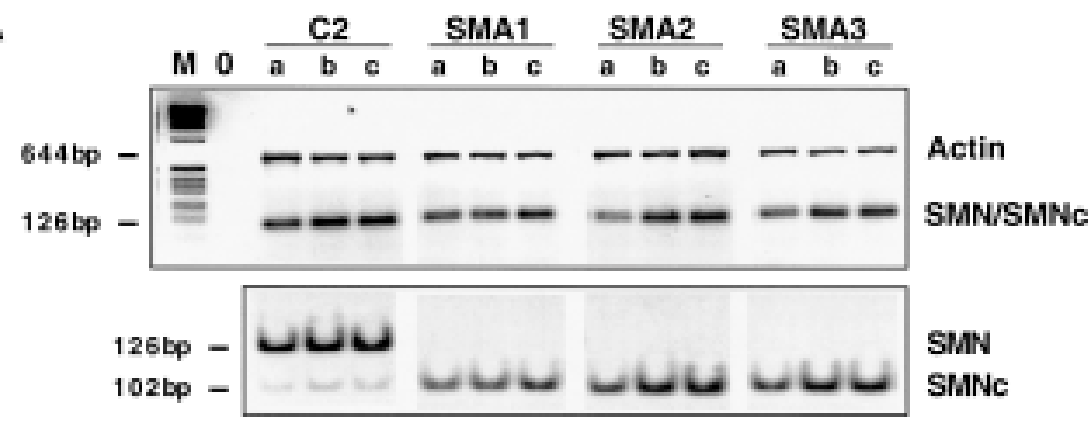

B
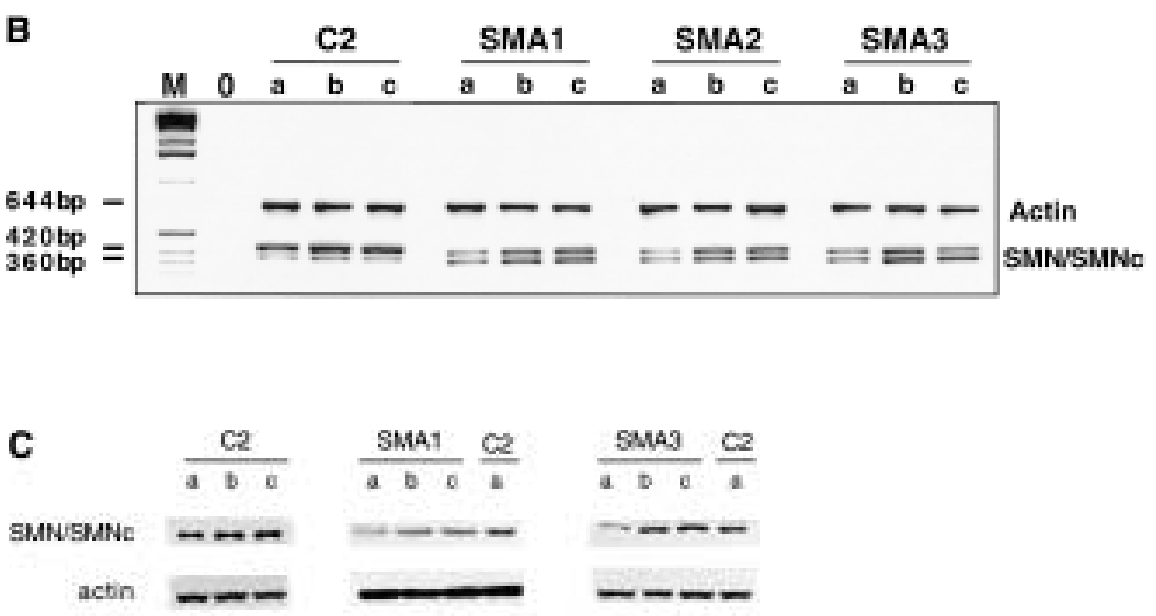

Fig. 7. Induction of SMNc gene expression in interferon (IFN)-treated fibroblasts from Spinal muscular atrophy (SMA) individuals. (A) Total RNA from fibroblasts of control (C2) and SMA patients (SMA1, SMA2, SMA3), either untreated (a), treated with IFN- $\beta(1000 \mathrm{U} / \mathrm{ml})$ for $8 \mathrm{hr}(\mathrm{b})$, or treated with IFN- $\gamma(1000 \mathrm{U} / \mathrm{ml})$ for $4 \mathrm{hr}$ (c), were analyzed for SMN and SMNc expression by reverse transcription-polymerase chain reaction (RT-PCR) experiments as described above. (B) RT-PCR experiments were performed using the same RNA samples, but another pair of

the disease, further studies will be performed to determine the possibility of a therapeutic role of IFNs in SMA, by restoring expression of SMNc.

\section{Acknowledgments}

We thank J. Wietzerbin and J. Sancéau for their constant support and advice; and C. Silvestri, N. Romquin, R. Hoch, B. Estournet, B. Reitter and M. Acker for their important help. This
SMN/SMNc primers, designed to generate a 420-bp and a 360-bp fragment corresponding to the full-lenght transcript of SMN/SMNc and to the alternatively spliced isoform lacking exon 7, respectively. (C) Total protein extracts (100 $\mu \mathrm{g} /$ lane) from fibroblasts of control (C2) and SMA patients (SMA1, SMA2, SMA3), either untreated (a), or treated for $16 \mathrm{hr}$ with IFN- $\beta(1000 \mathrm{U} / \mathrm{ml})$ (b), or with IFN- $\gamma(1000 \mathrm{U} / \mathrm{ml})$ (c) were analyzed by Western blots analysis, as previously described in Fig. 1, using the anti-SMN and anti-actin antibodies.

work was supported by INSERM and the "Association Française contre les Myopathies". S.B. was supported by a fellowship award from the "Association Française contre les Myopathies".

\section{References}

1. Lefebvre S, Bürglen L, Reboullet S, et al. (1995) Identification and characterization of a spinal muscular atrophy-determining gene. Cell 60: 155-165. 
2. Liu Q, Fischer U, Wang F, Dreyfuss G. (1997) The spinal muscular disease gene product, SMN, and its associated protein SIPl are in a complex with spliceosomal snRNP proteins. Cell 90: 1013-1021.

3. Fischer U, Liu Q, Dreyfuss G. (1997) The SMNSIPl complex has an essential role in spliceosomal snRNP biogenesis. Cell 90: 1023-1029.

4. Van Der Steege G, Grootscholten PM, Cobben JM, et al. (1996) Apparent gene conversions involving the SMN gene in the region of the spinal muscular atrophy locus on chromosome 5. Am. J. Hum. Genet. 59: 834-838.

5. Campbell L, Potter A, Ignatius J, Dubowitz V, Davies K. (1997) Genomic variation and gene conversion in spinal muscular atrophy: implications for disease process and clinical phenotype. Am. J. Hum. Genet. 61: 40-50.

6. DiDonato CJ, Ingraham SE, Mendell JR, et al. (1997) Deletion and conversion in spinal muscular atrophy patients: is there a relationship to severity? Ann. Neurol. 41: 230-237.

7. Lefebvre S, Burlet P, Liu Q, et al. (1997) Correlation of severity with the SMN protein level in spinal muscular atrophy. Nature Genetics 16: 265-269.

8. Coovert DD, Le TT, McAndrew PE, et al. (1997) The survival motor neuron protein in spinal muscular atrophy. Hum. Mol. Genet. 6: 1205-1214.

9. Bürglen L, Lefebvre S, Clermont O, et al. (1996) Structure and organization of the human Survival Motor Neurone (SMN) gene. Genomics 32: 479-482.

10. Echaniz-Laguna A, Miniou P, Bartholdi D, Melki J. (1999) The promoters of the survival motor neuron gene (SMN) and its copy (SMNc) share common regulatory elements. Am. J. Hum. Genet. 64: 1365-1370.

11. Darnell JE, Jr, Kerr IM, Stark GR. (1994) Jak-STAT pathways and transcriptional activation in response to IFNs and other extracellular signaling proteins. Science 264: 1415-1421.

12. Tanaka N, Kawakami T, Taniguchi T. (1993) Recognition DNA sequences of interferon regulatory factor 1 (IRF-1) and IRF-2, regulators of cell growth and the interferon system. Mol. Cell Biol. 13: 4531-4538.

13. Williams BRG. (1991) Transcriptional regulation of interferon-stimulated genes. Eur. J. Biochem. 200: 1-11.

14. Taniguchi T, Lamphier MS, Tanaka N. (1997) IRF-1 : the transcription factor linking the interferon response and oncogenes. Biochim. Biophys. Acta 1333: M9-M17.

15. Nguyen H, Hiscott J, Pitha PM. (1997) The growing family of interferon regulatory factors. Cytokine Grow. Factor Rev. 8: 293-312.

16. Post GR, Dawson G. (1992) Characterization of a cell line derived from a human oligodendroglioma. Mol. Chem. Neuropathol. 16: 303-317.

17. Chirgwin JM, Przybyla AE, MacDonald RJ, Rutter WJ. (1979) Isolation of biologically active ribonucleic acid from sources enriched in ribonuclease. Biochemistry 18: 5294-5299.

18. Barbu V, Dautry F. (1990) Mevalonate deprivation alters the induction of fos and myc by growth factors. Oncogene 5: 1077-1080.

19. Noda M, Yoon K, Rodan GA. (1988) Cyclic AMP-mediated stabilization of osteocalcin mRNA in rat osteoblast-like cells treated with parathyroid hormone. J. Biol. Chem. 263: 1857418577.

20. Van der Steege G, Grootscholten PM, Van der Vlies P, et al. (1995) PCR-based DNA test to confirm clinical diagnosis of autosomal recessive spinal muscular atrophy. Lancet 345: 985-986.

21. Hochhaus A, Yan XH, Willer A, et al. (1997) Expression of interferon regulatory factor (IRF) genes and response to interferon- $\alpha$ in chronic myeloid leukaemia. Leukemia 11: 933-939.

22. Schindler C, Darnell JE. (1995) Transcriptional responses to polypeptide ligands: the JAKSTAT Pathway. Annu. Rev. Biochem. 64: 621651.

23. Harada H, Fujita T, Miyamoto M, et al. (1989) Structurally similar but functionally distinct factors, IRF-1 and IRF-2, bind to the same regulatory elements of IFN and IFN-inducible genes. Cell 58: 729-739.

24. Gennarelli M, Lucarelli M, Capon F, et al. (1995) Survival motor neuron transcript analysis in muscles from spinal muscular atrophy patients. Biochem. Biophys. Res. Commun. 213: 342348.

25. Lorson CL, Strasswimmer J, Yao JM, et al. (1998) SMN oligomerization defect correlates with spinal muscular atrophy severity. Nature Genetics 19: 63-66.

26. Pellizzoni L, Kataoka N, Charroux B, Dreyfuss G. (1998) A novel function for SMN, the spinal muscular atrophy disease gene product, in premRNA splicing. Cell 95: 615-624

27. Liu Q, Dreyfuss G. (1996) A novel nuclear structure containing the survival of motor neurons protein. EMBO J. 15: 3555-3565.

28. Matera AG, Frey MR. (1998) Coiled bodies and Gems: Janus or Gemini? Am. J. Hum. Genet. 63: 317-321.

29. Sen GC, Ransohoff RM. (1993) Interferoninduced antiviral actions and their regulation. Adv. Virus Res. 42: 57-102.

30. Pestka S, Langer AJ, Zoon K, Samuel C. (1987) Interferons and their actions. Annu. Rev. Biochem. 56: 727-777.

31. De Maeyer E, De Maeyer-Guignard J. (1988) Interferons and Other Cytokines. John Wiley and Sons, NY.

32. Vilcek J, Sen GC. (1996) Fields in Virology. Fields BN, Knipe PM, Howley PM, et al. (eds.) Lippincott-Raven Publishers, city, 561 (of chapter) 